\title{
Prevalence of plasmid-mediated quinolone resistance determinants in Citrobacter freundii isolates from Anhui province, PR China
}

\author{
Correspondence \\ Zizhong Xiong \\ xiongzizhong@126.com \\ $\mathrm{Xu} \mathrm{Li}$ \\ aylixu@yahoo.com.cn
}

\section{Yibo Shao, ${ }^{1}$ Zizhong Xiong, ${ }^{1}$ Xu Li, ${ }^{1}$ Lifen Hu, ${ }^{1}$ Jilu Shen, ${ }^{2} \mathrm{Tao} \mathrm{Li}^{2}$ Fupin $\mathrm{Hu}^{3}$ and Shudan $\mathrm{Chen}^{3}$}

\author{
${ }^{1}$ Department of Infectious Diseases, The First Affiliated Hospital, Anhui Medical University, \\ Hefei 230022, PR China \\ ${ }^{2}$ Department of Clinical Laboratory, The First Affiliated Hospital, Anhui Medical University, \\ Hefei 230022, PR China \\ ${ }^{3}$ Institute of Antibiotics, Huashan Hospital, Fudan University, 12 M. Wulumuqi Road, \\ Shanghai 200040, PR China
}

Received 9 May 2011

Accepted 1 August 2011

\begin{abstract}
This study was conducted to detect and analyse the presence of plasmid-mediated quinolone resistance (PMOR) determinants $\left[q n r\right.$, aac $\left(6^{\prime}\right)-l b-c r$ and $\left.q e p A\right]$ among Citrobacter freundii isolates from patients in Anhui province, PR China. During 2009-2010, 31 C. freundii strains were collected from various hospital units and patient specimens. Using PCR, qnr genes were detected in eight isolates, but aac $\left(6^{\prime}\right)-l b-c r$ and $q e p A$ genes were not found. The genes qnrA1, qnrB1, qnrB2, qnrB4, qnrB10 and qnrB24 were present in 6.5, 3.2, 6.5, 3.2, 3.2 and $3.2 \%$ of $C$. freundii isolates, respectively. A new subgene of $q n r B$ variant ( $q n r B 24)$ was found and identified for what we believe to be the first time. PFGE after Xbal digestion of genomic DNA indicated that $q n r$-positive strains were not clonally related. Conjugation experiments were conducted to determine whether the qnr-carrying plasmids were self-transferable, and plasmids of transconjugants were extracted and analysed. The qnr genes were transferred from three clinical isolates to their transconjugants. Two qnrA1 genes transferred quinolone resistance with a plasmid of $\sim 11 \mathrm{~kb}$, whilst the size of the plasmid carrying the qnrB4 gene was $\sim 64 \mathrm{~kb}$. The susceptibility of positive isolates and transconjugants was tested using an agar dilution method according to Clinical and Laboratory Standards Institute guidelines, and the MICs of ciprofloxacin and levofloxacin were determined using Etest strips. Most isolates with qnr genes were resistant to fluoroquinolones and other antimicrobial agents. The MICs of transconjugants showed reduced susceptibility to fluoroquinolones.
\end{abstract}

\section{INTRODUCTION}

Fluoroquinolones are broad-spectrum antimicrobial agents currently effective in the treatment of a wide range of infections (Hopkins et al., 2005). Quinolones and fluoroquinolones are used extensively in both human and veterinary medicine and are therefore found as residues in the environment. This widespread use has been associated with increased levels of quinolone resistance, particularly in the last 10 years (Robicsek et al., 2006a). However, resistance is emerging in both production (Webber \& Piddock, 2001) and companion (Cohn et al., 2003; Pomba et al., 2009) animals. During these years, the extensive use and misuse of fluoroquinolones has

Abbreviations: PMOR, plasmid-mediated quinolone resistance; QRDR, quinolone resistance-determining region.

The GenBank/EMBL/DDBJ accession number for the qnrB24 sequence of Citrobacter freundii is HM192542. become a driver of both chromosome-encoded and plasmidencoded mechanisms of quinolone resistance (PMQR), with a potential selective advantage for PMQR determinants. PMQR determinants also play a role in the tight association between quinolone resistance and resistance to other antimicrobial agents.

PMQR genes ( $q n r)$ have been reported worldwide (Nordmann \& Poirel, 2005; Wang et al., 2008). The first $q n r$ determinant was reported in a clinical isolate of Klebsiella pneumoniae from the USA in 1998 (Martínez-Martínez et al., 1998). qnr genes have now been identified widely in various enterobacterial species, in both community and nosocomial settings (Robicsek et al., 2006a). Robicsek et al. (2006b) screened 313 ceftazidime-resistant Enterobacteriaceae isolates obtained in the USA from 1999 to 2004 for all three known $q n r$ genes. A $q n r$ gene was present in $20 \%$ of $K$. pneumoniae isolates, $31 \%$ of Enterobacter sp. isolates and 
$4 \%$ of Escherichia coli isolates. PMQR genes were significantly more prevalent in Enterobacteriaceae (Robicsek et al., 2006a; Ma et al., 2009). Jacoby et al. (2008) found various $q n r$ genes differing from each other by $\geqslant 40 \%$ in nucleotide sequence, identified in different species of Enterobacteriaceae. Within each family, minor $(\leqslant 10 \%)$ variation in sequence has defined a growing number of alleles (Jacoby et al., 2008). The Qnr proteins belong to the pentapeptide repeat family, which protects the DNA gyrase and topoisomerase IV from inhibition by quinolones. The aminoglycoside acetyltransferase variant $\mathrm{AAC}\left(6^{\prime}\right)-\mathrm{Ib}-\mathrm{cr}$ is capable of acetylating and subsequently reducing the activity of norfloxacin and ciprofloxacin. The recently described fluoroquinolonespecific efflux pump protein QepA is involved in pumping fluoroquinolones out of bacterial cells (Yamane et al., 2007). In recent years, these PMQR genes have been found in various bacteria.

Citrobacter freundii, a pathogen that is increasingly frequently causing nosocomial infections, is becoming multiresistant. Park et al. (2007) found that the prevalence of $q n r$ genes was $38.4 \%$ in 138 C. freundii isolates, whilst Bae et al. (2010) found qnrB22 and qnrB23 genes in Citrobacter werkmanii and $C$. freundii. These studies found that $C$. freundii often has PMQR determinants and some confer resistance to multiple drugs, and that qnr genes and other determinants are widely distributed in human clinical isolates of the family Enterobacteriaceae around the world (Park et al., 2007). The current study was thus designed to investigate the prevalence and transmission of PMQR determinants among C. freundii in Anhui province, PR China.

\section{METHODS}

Strains, plasmids and growth conditions. In total, 31 C. freundii strains were isolated from 2009 to 2010 at the First Affiliated Hospital of Anhui Medical University, PR China. The azide-resistant E. coli $\mathrm{J} 53$ strain $\left(\right.$ E. coli $\mathrm{J} 53 \mathrm{Az}^{\mathrm{R}}$ ) was chosen as the recipient strain for conjugation experiments. Strains were routinely grown in LuriaBertani broth. Culture plates contained Mueller-Hinton agar.

Susceptibility testing. Antimicrobial susceptibility to various antibiotics was determined by agar dilution on Mueller-Hinton agar plates, according to Clinical and Laboratory Standards Institute guidelines (CLSI, 2009a, b). Quality control for MICs was performed using the reference strain E. coli ATCC 25922. The MICs of ciprofloxacin and levofloxacin were determined using Etest strips according to the manufacturer's instructions.

PCR amplification and sequencing. All the isolates were screened for the genes $q n r A, q n r B, q n r S, q n r C, q n r D, a a c\left(6^{\prime}\right)-I b-c r$ and $q e p A$ by multiplex PCRs, using the primers shown in Table 1. Positive and negative controls were included. Positive PCR products were confirmed by sequence analysis. Sequences were analysed using the DNASTAR software package and compared with sequences deposited in GenBank.

Transfer of PMQR genes and plasmid characterization. The mechanism of PMQR transfer from qnr-positive C. freundii isolates to $E$. coli $\mathrm{J}_{53} \mathrm{Az}^{\mathrm{R}}$ was examined by conjugation experiments
(Martínez-Martínez et al., 1998). To avoid the development of spontaneous chromosomal mutations to fluoroquinolone resistance in the recipients, transconjugants were selected on Mueller-Hinton agar plates containing ampicillin $\left(64 \mu \mathrm{g} \mathrm{ml}^{-1}\right)$ with sodium azide $\left(200 \mu \mathrm{g} \mathrm{ml}^{-1}\right)$. Conjugation experiments were carried out at $37^{\circ} \mathrm{C}$. The transconjugant isolates were also screened by PCR for $q n r$ genes. Plasmid DNA was extracted from transconjugants and subjected to electrophoresis on a $0.9 \%(\mathrm{w} / \mathrm{v})$ agarose gel with ethidium bromide at $120 \mathrm{~V}$ for $1 \mathrm{~h}$. The size of plasmid was estimated by comparison with plasmid molecular size standards from E. coli strain V517.

PFGE. PFGE analysis of XbaI-digested (Promega) genomic DNA was performed (Gautom, 1997). The results of PFGE were analysed according to Tenover et al. (1995).

\section{RESULTS AND DISCUSSION}

\section{Screening for the PMQR gene}

The prevalence of $q n r$ genes among the screened isolates was $25.8 \%(8 / 31)$ in this study. qnrA1, qnrB1, qnrB2, $q n r B 4, q n r B 10$ and $q n r B 24$ were present in $6.5,3.2,6.5,3.2$, 3.2 and $3.2 \%$ of $C$. freundii isolates, respectively. Other $\mathrm{PMQR}$ genes were negative in these isolates. Sequence analysis revealed that the $q n r B$ gene of isolate 3 had a maximal nucleotide identity of $96.7 \%$ compared with the qnrB10 gene of C. werkmanii (GenBank accession no. EU136184). Three nucleotide changes were observed. The $\mathrm{C} \rightarrow \mathrm{A}$ change at nt 139 resulted in Leu $\rightarrow$ Met, $\mathrm{C} \rightarrow \mathrm{T}$ at nt 257 produced an $\mathrm{Ala} \rightarrow \mathrm{Val}$ change, and $\mathrm{A} \rightarrow \mathrm{G}$ at nt 670 produced an Ile $\rightarrow$ Val change. Hence, we propose that $q n r B$ is designated qnrB24, a new variant of the $q n r B$ gene, in accordance with the $q n r$ nomenclature rules of Jacoby et al. (2008).

\section{Results of PFGE}

The PFGE patterns of the eight PMQR-positive isolates appeared to be different from each other, which suggested that these isolates were not clonally related.

\section{Conjugation experiments and plasmid analysis}

$q n r$ genes were successfully transferred from three clinical isolates (isolates 4, 13 and 23) to their transconjugants. Transconjugants 4 and 13 with the qnrAl gene harboured a single plasmid of $\sim 11 \mathrm{~kb}$, whilst transconjugant 23 with the qnrB4 gene contained a plasmid of $\sim 64 \mathrm{~kb}$. Among these $q n r$-positive isolates, qnrA genes could be transferred by conjugation to the recipient $E$. coli $553 \mathrm{Az}^{\mathrm{R}}(2 / 2,100 \%)$. In contrast, $q n r B$ genes were transferred successfully in only one isolate for qnrB4 $(1 / 6,16.7 \%)$.

\section{Antimicrobial susceptibility testing}

In addition to being resistant to quinolones, qnr-positive clinical isolates were also resistant to various antibiotics, including aminoglycosides and $\beta$-lactams. Isolates $4,5,7$, $12,13,22$ and 23 had a ciprofloxacin MIC of $8-64 \mu \mathrm{g} \mathrm{ml}^{-1}$, 
Table 1. Primers used for PCR detection of PMQR genes

\begin{tabular}{|c|c|c|c|}
\hline Gene & Primer sequence $\left(5^{\prime} \rightarrow 3^{\prime}\right)^{*}$ & Annealing temperature $\left({ }^{\circ} \mathrm{C}\right)$ & Amplicon size (bp) \\
\hline \multirow[t]{2}{*}{$q n r A 1-6$} & F: TCGGCAAAGGTCAGGTCACAGC & 50 & 479 \\
\hline & R: GCAAGAGGATTTCTCACGCCAGGAT & & \\
\hline$q n r B 1$ group & R: CCCTTTCTGGCTGGCTTTCAC & & \\
\hline \multirow[t]{2}{*}{ qnrB4 group } & F: ATCACCACCCGCACCT & 50 & 242 \\
\hline & R: TCTAAATCGCCCAGTTCC & & \\
\hline qnrB5 group & R: CCTAACTCCGAATTGGTC & & \\
\hline \multirow[t]{2}{*}{ qnrB8 group } & F: AGCCAGAAAGGGTGAAT & 50 & 318 \\
\hline & R: ATCGAACCTAACG & & \\
\hline \multirow[t]{2}{*}{$q n r S 1$ and $q n r S 3$} & F: CACTTTGATGTCGCAGAT & 50 & 471 \\
\hline & R: CAACACTACCCAGTGCTT & & \\
\hline qnrS2 & F: ATCGCTCCATGGGACTC & 50 & 216 \\
\hline$q n r B-T$ & R: TTGGATCCAACGCACATTTGCAGATGTTAT & & \\
\hline \multirow[t]{2}{*}{$q n r C$} & F: GAATTATTCCATAAAACG & 55 & 509 \\
\hline & R: GCTCCCAAAAGTCATC & & \\
\hline \multirow[t]{2}{*}{$a a c\left(6^{\prime}\right)-I b-c r$} & F: TTGCGATGCTCTATGAGTGG & 51 & 478 \\
\hline & R: CTCGAATGCCTGGCGTGTTT & & \\
\hline \multirow[t]{2}{*}{$q e p A$} & F: GCAGGTCCAGCAGCCGGTAG & 55 & 218 \\
\hline & R: CTCGAATGCCTGGCGTGTTT & & \\
\hline \multirow[t]{2}{*}{$q n r D$} & F: CGAGATCAATTTACGGGGAATA & 55 & 582 \\
\hline & R: AACAAGCTGAAGCGCCTG & & \\
\hline
\end{tabular}

${ }^{\star} \mathrm{F}$, Forward; R, reverse.

whilst isolate 7 had a ciprofloxacin MIC of $1 \mu \mathrm{g} \mathrm{ml}^{-1}$. The overall resistance rate of all $q n r$-positive isolates to ciprofloxacin was $87.5 \%$.

The percentages of isolates with intermediate resistance or resistance to cefotaxime, amikacin, ceftazidime, cefepime and gentamicin were $75,37.5,62.5,37.5$ and $87.5 \%$, respectively. All isolates were susceptible to imipenem (Table 2). All transconjugants showed reduced susceptibility to fluoroquinolones compared with the recipient $E$. coli $\mathrm{J} 53 \mathrm{Az} \mathrm{z}^{\mathrm{R}}$. The qnr-containing transconjugants conferred decreased susceptibility to ciprofloxacin (MIC range 0.19 $1.0 \mu \mathrm{g} \mathrm{ml}^{-1}$ ) and levofloxacin (MIC range $0.19-0.75 \mu \mathrm{g}$ $\mathrm{ml}^{-1}$ ), representing 10-23-fold increases compared with those of the recipient, which had a ciprofloxacin MIC of $0.016 \mu \mathrm{g} \mathrm{ml}^{-1}$ and a levofloxacin MIC of $0.032 \mu \mathrm{g} \mathrm{ml}{ }^{-1}$. Some were also resistant to other antimicrobial agents. The co-transferred plasmid-mediated resistance to non-fluoroquinolone antimicrobial agents is shown in Table 2.

This study examined the plasmid-mediated mechanisms of fluoroquinolone resistance in $31 \mathrm{C}$. freundii isolates obtained from Anhui, PR China. Our results found that the prevalence of $q n r$ genes was $25.8 \%$. The $q n r A$ gene found was $q n r A 1$, whilst the $q n r B$ genes comprised $q n r B 1, q n r B 2$, $q n r B 4, q n r B 10$ and $q n r B 24$ in C. freundi. These results are consistent with conclusions in previous studies (Park et al., 2007). In this study, we found a novel $q n r B$ variant, $q n r B 24$, and this is also the first report, to our knowledge, of the presence of qnrB10 in C. freundii in Anhui, PR China. We also found that the MICs of fluoroquinolones for clinical isolates were higher than those for their transconjugants. Many studies have indicated that chromosomal quinolone resistance-determining region (QRDR) mutations in gyrA and parC play an important role in mediating high-level quinolone resistance (Eaves et al., 2004). Fang et al. (2009) found that Enterobacteriaceae harbouring qnrB4 or qnrB6 were highly resistant to all the fluoroquinolones tested. This high-level resistance was associated with multiple chromosomal substitutions in gyrA and parC. Alterations at codons Ser83 and Asp87 in GyrA and at codons Ser80 and Glu84 in ParC were observed in these isolates. In fact, some reports (Martínez-Martínez et al., 2003; Tran et al., 2005) have suggested that $q n r$ confers only low-level resistance to quinolone and that its main contribution is to facilitate the development of QRDR mutations. The mechanism of action of the QRDR might cause various MICs of fluoroquinolone in $q n r$-positive isolates and transconjugants. Previous studies have also shown variable $q n r$ expression in transconjugants, and variable promoter strengths can account for differences in MICs (Xu et al., 2007). In this study, we found that one 
Table 2. Resistance profiles of clinical C. freundii isolates, the recipient strain E. coli $\mathrm{J} 53 \mathrm{Az} \mathrm{z}^{\mathrm{R}}$ and transconjugants

CIP, Ciprofloxacin; LVX, levofloxacin; CL, chloromycetin; PIP, piperacillin; CZ, cefazolin; CAZ, ceftazidime; CTX, cefotaxime; FEP, cefepime; IMP, imipenem; GEN, gentamicin; AMK, amikacin.

\begin{tabular}{|c|c|c|c|c|c|c|c|c|c|c|c|}
\hline \multirow[t]{2}{*}{ Strain (gene) } & \multicolumn{11}{|c|}{$\operatorname{MIC}\left(\mu \mathrm{g} \mathrm{ml}^{-1}\right)$} \\
\hline & CIP & LVX & CL & PIP & $\mathrm{CZ}$ & CAZ & CTX & FEP & IMP & GEN & AMK \\
\hline Isolate 3 (qnrB24) & 8 & 32 & 128 & $>128$ & 128 & $>128$ & 128 & 64 & 1 & 32 & 64 \\
\hline Isolate 4 (qnrA1) & 32 & 32 & 8 & 64 & 128 & 128 & $>128$ & 4 & 0.5 & 64 & 16 \\
\hline Isolate $5(q n r B 1)$ & 8 & 1 & 128 & 128 & 128 & 2 & 2 & 4 & 0.5 & 16 & 16 \\
\hline Isolate 7 (qnrB2) & 1 & 4 & 64 & $>128$ & 128 & 16 & 8 & 0.0625 & 0.5 & 0.125 & 2 \\
\hline Isolate $12(q n r B 2)$ & 32 & 64 & 16 & 64 & 128 & 16 & 32 & 16 & 0.5 & 16 & 16 \\
\hline Isolate 13 (qnrA1) & 64 & 32 & 32 & $>128$ & $>128$ & 16 & 64 & 4 & 0.5 & 64 & 8 \\
\hline Isolate $22(q n r B 10)$ & 8 & 4 & 32 & 128 & 8 & 4 & 8 & 2 & 2 & 128 & 32 \\
\hline Isolate 23 (qnrB4) & 64 & 32 & $>128$ & 64 & $>128$ & 16 & 64 & 16 & 1 & 64 & 32 \\
\hline E. coli $\mathrm{J} 53 \mathrm{Az}^{\mathrm{R}}$ & $0.016^{*}$ & $0.032^{*}$ & 8 & 2 & 2 & 0.25 & 0.0625 & 0.0625 & 0.25 & 0.25 & 0.5 \\
\hline Transconjugant 4 & $0.38^{\star}$ & $0.38^{\star}$ & 8 & 64 & 128 & 64 & 128 & 4 & 1 & 2 & 16 \\
\hline Transconjugant 13 & $0.19^{*}$ & $0.19^{*}$ & 8 & 128 & 16 & 16 & 32 & 4 & 0.25 & 64 & 8 \\
\hline Transconjugant 23 & $1.0^{*}$ & $0.75^{\star}$ & 128 & 64 & $>128$ & 16 & 64 & 8 & 0.25 & 64 & 16 \\
\hline
\end{tabular}

${ }^{\star}$ Etest results.

isolate did not confer the ciprofloxacin resistance phenotype, indicating that using quinolone or fluoroquinolone breakpoints as markers for detection might underestimate the prevalence of PMQR. This finding could have clinical implications, as $q n r$ genes might promote further selection from low- to high-level resistance when quinolones are used. Conjugation experiments suggested the occurrence of horizontal mobility of the $q n r$ genes. Susceptibility testing of all the transconjugants demonstrated the transfer of quinolone resistance and hence plasmid-mediated resistance determinants. The qnr genes were located in conjugative plasmids, so the genes could increase bacterial resistance to fluoroquinolones through the transmitted plasmid. As a method for studying epidemics, the PFGE results showed that these isolates were not clonally related. The plasmids carrying $q n r$ genes varied widely in size and associated multiresistance. The transconjugant susceptibility testing results showed they were not only resistant to fluoroquinolones but also to $\beta$-lactams, aminoglycosides and other antibiotics. Genes for $q n r A$ and sometimes $q n r B$ have been found as part of complex sull-type integrons containing a presumed recombinase gene, orf513 (Robicsek et al., 2006a). The $q n r$ gene is probably aided by its genetic linkage to resistance determinants for various other antibiotics. A similar result was found in the results of Corkill et al. (2005). Two possible causes for the resistance change are as follows: (i) qnr-positive isolates often carry extended-spectrum $\beta$ lactamase or ampC genes; and (ii) the $q n r$ gene is often located on plasmids or integrons that include the genes $a a c$, cat, ampR, aar, dfr or aad (Li, 2005).

In conclusion, we believe this to be the first description of plasmid-mediated fluoroquinolone resistance in C. freundii isolates from Anhui province, PR China. In this survey, qnr genes, especially $q n r B$, were prevalent in $C$. freundii isolates from Anhui province, together with resistance to various other antimicrobial agents. We also found a new variant of $q n r B, q n r B 24$. We intend to study the function of qnrB24 and its genetic environment further in the future.

\section{ACKNOWLEDGEMENTS}

This work was supported in part by grants from the Key Technology Program of Ministry of Education, China (209059) and the Department of Education of Anhui province, PR China (KJ2011A180). We thank Professor Minggui Wang and Demei Zhu for providing the recipient strain E. coli $\mathrm{J} 53 \mathrm{Az} \mathrm{R}^{\mathrm{R}}$ and $E$. coli V517.

\section{REFERENCES}

Bae, I. K., Park, I., Lee, J. J., Sun, H. I., Park, K. S., Lee, J. E., Ahn, J. H., Lee, S. H. \& Woo, G. J. (2010). Novel variants of the $q n r B$ gene, qnrB22 and qnrB23, in Citrobacter werkmanii and Citrobacter freundii. Antimicrob Agents Chemother 54, 3068-3069.

CLSI (2009a). Performance Standards for Antimicrobial Disk Susceptibility Tests, 10th edn; Approved Standard. M02-A10. Wayne, PA: Clinical and Laboratory Standards Institute.

CLSI (2009b). Methods for Dilution Antimicrobial Susceptibility Tests for Bacteria that Grow Aerobically, 8th edn; Approved Standard. M07A8. Wayne, PA: Clinical and Laboratory Standards Institute.

Cohn, L. A., Gary, A. T., Fales, W. H. \& Madsen, R. W. (2003). Trends in fluoroquinolone resistance of bacteria isolated from canine urinary tracts. J Vet Diagn Invest 15, 338-343.

Corkill, J. E., Anson, J. J. \& Hart, C. A. (2005). High prevalence of the plasmid-mediated quinolone resistance determinant $q n r A$ in multidrug-resistant Enterobacteriaceae from blood cultures in Liverpool, UK. J Antimicrob Chemother 56, 1115-1117.

Eaves, D. J., Randall, L., Gray, D. T., Buckley, A., Woodward, M. J., White, A. P. \& Piddock, L. J. (2004). Prevalence of mutations within the quinolone resistance-determining region of $\operatorname{gyr} A, \operatorname{gyr} B$, parC, and 
parE and association with antibiotic resistance in quinolone-resistant Salmonella enterica. Antimicrob Agents Chemother 48, 4012-4015.

Fang, H., Huang, H., Shi, Y., Hedin, G., Nord, C. E. \& Ullberg, M. (2009). Prevalence of $q n r$ determinants among extended-spectrum $\beta$ lactamase-positive Enterobacteriaceae clinical isolates in southern Stockholm, Sweden. Int J Antimicrob Agents 34, 268-270.

Gautom, R. K. (1997). Rapid pulsed-field gel electrophoresis protocol for typing of Escherichia coli O157:H7 and other Gram-negative organisms in 1 day. J Clin Microbiol 35, 2977-2980.

Hopkins, K. L., Davies, R. H. \& Threlfall, E. J. (2005). Mechanisms of quinolone resistance in Escherichia coli and Salmonella: recent developments. Int J Antimicrob Agents 25, 358-373.

Jacoby, G., Cattoir, V., Hooper, D., Martínez-Martínez, L., Nordmann, P., Pascual, A., Poirel, L. \& Wang, M. (2008). qnr gene nomenclature. Antimicrob Agents Chemother 52, 2297-2299.

Li, X.-Z. (2005). Quinolone resistance in bacteria: emphasis on plasmid-mediated mechanisms. Int J Antimicrob Agents 25, 453-463.

Ma, J., Zeng, Z., Chen, Z., Xu, X., Wang, X., Deng, Y., Lü, D., Huang, L., Zhang, Y. \& other authors (2009). High prevalence of plasmidmediated quinolone resistance determinants $q n r, a a c\left(6^{\prime}\right)-I b-c r$, and $q e p A$ among ceftiofur-resistant Enterobacteriaceae isolates from companion and food-producing animals. Antimicrob Agents Chemother 53, 519-524.

Martínez-Martínez, L., Pascual, A. \& Jacoby, G. A. (1998). Quinolone resistance from a transferable plasmid. Lancet 351, 797-799.

Martínez-Martínez, L., Pascual, A., García, I., Tran, J. \& Jacoby, G. A. (2003). Interaction of plasmid and host quinolone resistance. J Antimicrob Chemother 51, 1037-1039.

Nordmann, P. \& Poirel, L. (2005). Emergence of plasmid-mediated resistance to quinolones in Enterobacteriaceae. J Antimicrob Chemother 56, 463-469.

Park, Y.-J., Yu, J. K., Lee, S., Oh, E.-J. \& Woo, G.-J. (2007). Prevalence and diversity of $q n r$ alleles in AmpC-producing Enterobacter cloacae, Enterobacter aerogenes, Citrobacter freundii and Serratia marcescens: a multicentre study from Korea. J Antimicrob Chemother 60, 868-871.
Pomba, C., da Fonseca, J. D., Baptista, B. C., Correia, J. D. \& Martínez-Martínez, L. (2009). Detection of the pandemic O25-ST131 human virulent Escherichia coli CTX-M-15-producing clone harboring the qnrB2 and aac $\left(6^{\prime}\right)-I b-c r$ genes in a dog. Antimicrob Agents Chemother 53, 327-328.

Robicsek, A., Jacoby, G. A. \& Hooper, D. C. (2006a). The worldwide emergence of plasmid-mediated quinolone resistance. Lancet Infect Dis 6, 629-640.

Robicsek, A., Strahilevitz, J., Sahm, D. F., Jacoby, G. A. \& Hooper, D. C. (2006b). qnr prevalence in ceftazidime-resistant Enterobacteriaceae isolates from the United States. Antimicrob Agents Chemother 50, 28722874.

Tenover, F. C., Arbeit, R. D., Goering, R. V., Mickelsen, P. A., Murray, B. E., Persing, D. H. \& Swaminathan, B. (1995). Interpreting chromosomal DNA restriction patterns produced by pulsed-field gel electrophoresis: criteria for bacterial strain typing. J Clin Microbiol 33, 2233-2239.

Tran, J. H., Jacoby, G. A. \& Hooper, D. C. (2005). Interaction of the plasmid-encoded quinolone resistance protein $q n r$ with Escherichia coli DNA gyrase. Antimicrob Agents Chemother 49, 118-125.

Wang, A., Yang, Y., Lu, Q., Wang, Y., Chen, Y., Deng, L., Ding, H., Deng, Q., Wang, L. \& Shen, X. (2008). Occurrence of qnr-positive clinical isolates in Klebsiella pneumoniae producing ESBL or Amp C-type $\beta$-lactamase from five pediatric hospitals in China. FEMS Microbiol Lett 283, 112-116.

Webber, M. \& Piddock, L. J. (2001). Quinolone resistance in Escherichia coli. Vet Res 32, 275-284.

Xu, X., Wu, S., Ye, X., Liu, Y., Shi, W., Zhang, Y. \& Wang, M. (2007). Prevalence and expression of the plasmid-mediated quinolone resistance determinant qnrA1. Antimicrob Agents Chemother 51, 41054110.

Yamane, K., Wachino, J., Suzuki, S., Kimura, K., Shibata, N., Kato, H., Shibayama, K., Konda, T. \& Arakawa, Y. (2007). New plasmid-mediated fluoroquinolone efflux pump, QepA, found in an Escherichia coli clinical isolate. Antimicrob Agents Chemother 51, 3354-3360. 